\title{
Systematization of development transport systems indicators on the aviation example
}

\author{
Olga Borodina $^{1 *}$, Natalya Shatalova ${ }^{1}$ \\ ${ }^{1}$ Solomenko Institute of Transport Problems of the Russian Academy of Sciences, 199178 12-th Line \\ VO, 13 St.-Petersburg, Russian Federation
}

\begin{abstract}
The publication proposes a functional diagram of the connection of the air navigation system to the unified transport system as a subsystem for providing air transportation. This paper consists an analysis of the transport system development factors: goals and principles of building an air navigation system; activities of the trust and alliance in the domestic air transportation market; the need to determine the catchment areas of transport infrastructures. The main result of this publication is the concept of air navigation system development. It is given the concept of mathematical model indicators connection of air navigation system. The list of indicators is given, table "Proposed and real goals of the air navigation system", figure - 'Network indicator structure'.
\end{abstract}

\section{Introduction}

The transport system [1] is a complex of infrastructural objects in the system of relations between the participants in the transportation process. Air transport, being an element of a unified transport system, is used for the tasks of maintaining defence capability, developing government and experimental aviation and other purposes indicated in the Air Code of the Russian Federation. The most widely spread way of using air transport is to perform commercial air carriage.

The participants in the transportation process are representatives of the private sector of the economy (airlines, Airport Operations Unit - AOU), government agencies as airspace providers, government companies, research and aircraft manufacturing enterprises [2]. Active participants in the air transport process are representatives of the private sector of the economy and government authorities that form / build a system of relations in terms of the use of airspace for commercial purposes.

For the aviation industry, the technical and technological platform for the implementation of tasks Airspace Use Plan (AUP) is the air traffic management system (ATM) and the air navigation service system (ANS). ANS system, is an organizational system of rules for the provision of Communication, Navigation and Surveillance (CNS) Services along with the Global Navigation Satellite System (GNSS) as a technical platform. The Air Traffic Management consists of Air Traffic Control (ATC) and their navigation by through Air Navigation Services to points along the route during the implementation of this

\footnotetext{
*Corresponding author: borodinaov@gmail.com
} 
movement by the aircraft operator. Thus, both air traffic services are air navigation services for users and can be combined into the air navigation subsystem of the Russian Federation(ANS) (Fig. 1).

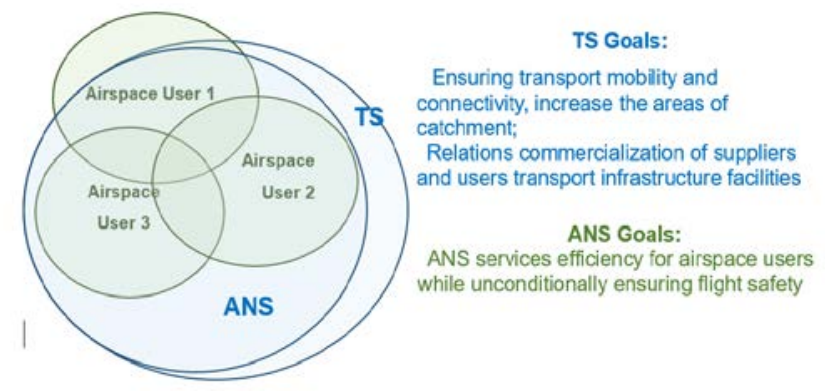

Fig. 1. Functional connection of TS with the ANS subsystem.

The Russian Federation ANS system is formed under the leadership of the RF Ministry of Transport and the direct participation of basic federal department of competence, such as the State Air Traffic Management Corporation of the Russian Federation (State ATM Group). In 2018, the ATM Group included the FSUE Department for Aeronautical Information, FSUE Department for Radio Equipment and Communications in Civil Aviation, FSUE Regional Technical Department for Aviation Information, Certification and Communications. Within the framework of the ANS system, radio technical flight support (RTOP) facilities are operated at the country's airports, which amounts to more than 20,000 units of RTOP and aviation telecommunication facilities [https://gkovd.ru].

The equipment of the system for organizing the use of airspace allows air traffic services (ATS) to be carried out on 928 air routes with a total length of over 700 thousand $\mathrm{km}$ [https://gkovd.ru], where the responsibility for ATS is assigned by the ICAO Intergovernmental Civil Aviation Organization to the Russian Federation. In an official document [https://gkovd.ru], the ANS aims to ensure national security, what is the target function RF Transport System.

\section{Analyse the RF situation for ANS development}

\subsection{Designed ANS}

The problems of the formation and functioning of the system for organizing air transportation, as in other sectors of the commercial air carriage, lie in the objective absence of tools for emergency interaction of the regulator / responsible person with the commercial division, with organizations performing the role of a supplier of transport services, and other participants. The regulator is not so flexible to the requirements of commercial enterprises and this fact naturally creates difficulties within the system. The objects of the ANS system have their own target functions and perform their own tasks airlines earn money, and the regulator provides a service for organizing safe traffic in the airspace and in the airfield area [3]. In the current version of the draft ANS Strategy [https://gkovd.ru], the regulator sets in its key development indicators the parameter "Economic efficiency of consumers of air navigation services", which causes an imbalance of interests of the system participants. So if the ANS system is built for the task of creating a high-quality product "air navigation service", then an indicator of the internal efficiency 
of the ANS system "access to the use of airspace in accordance with service tariff plans and the tasks of the state" is necessary (Table 1).

Table 1. Proposed and real goals of the air navigation system.

\begin{tabular}{|c|c|}
\hline ANS goal, version 7.1 dated 23.11.2017 & Proposed ANS goal \\
\hline 1. Safety & 1. Safety of ATM system \\
\hline 2. Economic efficiency of ANS users & $\begin{array}{c}\text { 2. User's responsibility of traffic safety in area of } \\
\text { airfield and airspace }\end{array}$ \\
\hline 3. Equitable access to the use of airspace & $\begin{array}{c}\text { 3. Airspace using rules with service tariff plans } \\
\text { accordance and state objectives }\end{array}$ \\
\hline 4. ANS economic efficiency & 4. ANS economic efficiency \\
\hline
\end{tabular}

The proposed ANS metric setting allows you to customize the following ANS development goals:

- safety only for ATM system,

- demand airport infrastructure capacity.

- the efficiency of the air traffic management and air traffic control system,

- the efficiency of the air flow management system.

The ICAO operation indicators [4] for building the mathematical model to connecting ANS's indicators (Tab. 1.) most popular to implementation. For example, the indication of capacity parameters, which, according to ICAO recommendations, consist of airspace capacity, aerodrome capacity and mixed capacity [4]. The allocating slots for airside and groundside users, based on the indication of the dynamic state of air and ground space, and solves the problem of "equitable access" to air transport resources

\subsection{Antitrust restrictions}

The next up-to date task of the system of organizing air transportation is the network of commercial relations between enterprises. Objectively, the goal of commercial companies is return on equity (ROE) or return on sales (ROS) [5]. Capital is not interested in such actions as: the acquisition of aircraft, long-term investments in air transport infrastructure and the airport complex, navigation equipment for air routes, communication and navigation facilities in airfield areas, capital investments in the technical re-equipment of ground airport services, etc.

The indicators of the airline's business profitability are on average $3.5-7 \%$ [6]. In order to level financial losses, these participants in the ANS system are forced to build commercial relations with partners. The system of commercial relations between the participants makes it possible to increase the economic efficiency of the transportation process in civil aviation due to a greater coverage of the market and an extensive network of partners [7]. The regulator of this system is the International Civil Aviation Association (IATA), as formalistic.

The world air transportation market is divided by three world alliances Sky Team, Oneworld and Star Alliance [8]. The alliances continue to use own booking systems, forcing airlines to ditch their distribution system for booking and sales in order to use offered technology and platforms. Alliances may come to operate in the domestic RF market. AEROFLOT, for example, is a member of the Sky Team alliance, and UTAIR has chosen Oneworld as a partner in conquering the domestic market. The Russian Federation is a party to the Warsaw Convention (1946), which does not allow foreign carriers to enter the domestic market without a government approval though. Warsaw Convention (1946) weakens the sales policy of airlines, but can cutch the onslaught of alliances to conquer the 
RF domestic market. The legalization of the Montreal Convention of 1975 may lead out the sale of the "air" of our country between these alliances [9].

The admission to the domestic market of the alliances of transnational world leaders for their work to conquer the national market of the Russian Federation completely depends on the policy of the regulator and the goal of developing the systems and subsystems of the Transport System of the Russian Federation. The trend of conquering spheres of influence in the domestic air transportation market can be traced today down to the area of attraction the Murmansk airport [10,11], which is of strategic importance for the development of the Northern Sea Route $[10,11]$.

However, if the emergence of alliances is a planned mechanism of state regulation of the system of relations in the market, then this fact will become an impetus for the development of the internal transportation market. Controlling the parameters of the performed transport work of both: an alliance and an individual carrier - is possible through a system of indicators of the commercial activity of enterprises in the external and internal markets $[7,8,9,12]$. The balance of value of the operational concept implemented by the airline in the region can be shifted towards profit, or it can be of strategic importance in the spatial development of the region of attraction [7, 12]. The variety of transport enterprises commercial tasks should be objectively reflected in the forms of reports on the performed transport work. The ICAO statistical reporting system offers maximum transparency to the areas of commercial activity of airlines [13].

\subsection{Catchment area and statistic programme}

The spatial development of territories is priority for the RF TS, and the ramification of the route network of transportation and the tools of the cargo delivery system is the task of transport enterprises as objects of the TS. For example, the contribution of the airline (social benefits) to increasing the aviation mobility of the country's population, assessed today by the TCH reporting forms (column 1) and ICAO reporting forms (column 2), shows that with the same passenger traffic indicator RPK (revenue passenger kilometres, pass $\backslash$ thousand $\mathrm{km}$ ), the number of passengers who received the aviation product of the industry (transportation) may be different. (Table 2).

Table 2. The various forms of airline's contribution statistical reporting.

\begin{tabular}{|c|c|c|c|c|}
\hline Route & $\begin{array}{c}\text { Aircraft } \\
\text { type }\end{array}$ & $\begin{array}{c}\text { Passenger traffic } \\
\text { (RPK) }\end{array}$ & $\begin{array}{c}\text { Amount of } \\
\text { services } \\
\text { (RF form 32) }\end{array}$ & $\begin{array}{c}\text { Amount of } \\
\text { services (form } \\
\text { «B» ICAO) }\end{array}$ \\
\hline $\begin{array}{c}\text { Moscow-Sochi (1270 } \\
\text { km) }\end{array}$ & CRJ200 & 558800 pax $\backslash \mathrm{km}$ & 44 pass. & 44 pass.. \\
\hline $\begin{array}{c}\text { Novosibirsk- } \\
\text { Novokuznetsk (400 } \\
\mathrm{km})-\begin{array}{c}\text { Abakan (870 } \\
\mathrm{km})\end{array}\end{array}$ & CRJ200 & 55800 pax $\backslash \mathrm{km}$ & 44 pass. & 88 pass. (44+44) \\
$(17600+32280)$ & & \\
\hline
\end{tabular}

Accounting for the products produced by the industry is accurate on form. The spatial development indicators should be reflected the contribution of the TS participants to the development of the system. The source [15] sets out in detail the principles of statistical accounting for the product of a transport company and the effect of spatial development that the TS can obtain with the same indicators of the performed transport work. The methodology for accounting for the final contribution to the development of the industry is not systematized today $[12,15]$, however, its tasks are solved by the system of subsidizing transportation within the framework of the Federal Target Program "Regional Transportation". Moreover, information about the needs of the population in aviation 
mobility by geographic points is closed and constitutes a commercial secret of the airline [12]. You can collect information for the analysis of up-to-date data using the forms of statistical accounting recommended by ICAO.

And finally, it is difficult for the state, as an airspace provider and ANS system regulator, to be the only provider of air navigation services, but this market is too attractive to outsource it. One of the groups of indicators for the development of the TS should be indicators reflecting the activity and efficiency of public-private partnerships in the operation of air transport infrastructure facilities.

\section{Concept of ANS development indicators}

ANS function of and place of them TS with severe conflicts of interest between their managers and dispersed shareholders $[8,12,13,14,15]$. The currently forming ANS is the main tool for regulating the relationship between the supplier and users of the airspace. ANS must be reflected the reliability of the functioning of the complex of objects.

The proposal concept of ANS developed are in indicators with efficiency:

A. to increase the airport catchment area;

B. to implementation an ANS services with tariffs plan accordance to state objectives;

C. regulation system of responsibility for safety operation procedure.

D. to implementation a public-private partnership in the operation of air transport infrastructure facilities.

\section{Model of ANS indicator's}

The development indicators has modelling on result of analyses RF situation with ICAO's Aviation System Block Upgrades recommendations and practice [4].

The patterns of indicators on the Fig. 2. indicated A, B, C, D group factors.

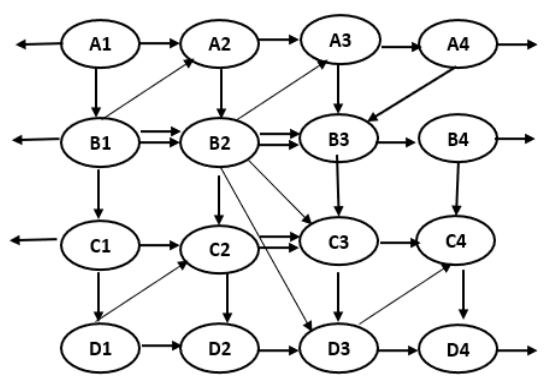

Fig. 2. Indicators network structure.

A group. "Catchment area": A1 - hourly and daily of air traffic flow intensity, A2 directions between the points of departure and arrival (O\&D). B group. "ATM system": B1 - the air traffic intensity on the routes and at points in the airspace, B2 - amount of aircraft simultaneously present in the waiting area, B3 - daily workload along the routes plan / fact, B4 - the distribution of aircraft by level, the time of using the waiting areas, B5 - time of use of arrival / departure routes. C group. "Safety is monitored by indicators": C1 amount of potential conflict situations, C2 - amount of a separation standards violations, C3 - amount of a dangerous encounters, C4 - amount of a violations of standard procedures, C5 
- amount of a collisions with airborne. D group. "Capacity parameters": D1 - SLA contract on use airspace capacity, D2 - SLA contract on use aerodrome capacity area.

All data modelling item's A(i;j), B(i;j) etc. is equal to the average expected value of all operations used in pair (i;j) per circle (slot allocation).

For every moment time ( $\mathrm{pt}$;), matrix of operations is a sequence of realizations a random variable having a Poisson distribution ( $£$ ) with the parameter [14]. The accumulation of statistics of the parameter $(\mathfrak{f})$ will mean setting up the control links of the ANS system. It is the next step of researching.

\section{Conclusion}

This work described the analysis of the main tasks of the subsystem of RF commercial air transportation industry. The goal of ANS include not only in ensuring the safety of air traffic, but also meeting the need for technical and technological equipment for air navigation services for air routes. The article to ordered the providing availability of publicprivate partnership contracts for the operation of infrastructure facilities within the framework of antimonopoly regulation of access of airline alliances to the domestic market.

The article consists the main ANS indicators recommendations and developed the network model of indicators accordance with ICAO recommendation and practice.

\section{References}

1. I. Malygin, V. Komashinskiy, A. Asaul, TRP 20, pp. 25-30 DOI:10.1016/j.trpro.2017.01.006 (2017)

2. V.G. Afanasiev, Sc. bulletin of the MSTU of CA 214, 16-20, ISSN: 2079-0619 (2015)

3. V. Komashinskiy, I. Malygin, O. Korolev, TRP 50, 273-279 DOI10.1016/j.trpro.2020.10.033 (2020)

4. ICAO doc 9883, Manual on Global Performance of the Air Navigation System ISBN 978-92-9231-460-6 (2009)

5. Su-J. Chen, M-H. Chen, H-L. Wei. Journal of HTM 33, 1-10 DOI10.1016/j.jhtm.2017.08.001 (2017)

6. IATA, Business Intelligence and Statistics (2017)

7. M. Renolda, J. Kuljaninb, M. Kalib, TRP 43, 178-187 DOI 10.1016/j.trpro.2019.12.032 (2019)

8. O. Lordana, R. Klophausb, Measuring the vulnerability of global airline alliances to member exits, TRP 25, 7-16 DOI 10.1016/j.trpro.2017.05.189 (2017)

9. V.G. Afanasiev, Air policy and international air transport regulation, Scientistic bulletin of the MSTU of CA 170, pp.13-16, ISSN: 2079-0619 (2011)

10. V. Sergeev, I. Ilin, Al. Fadeev, TRP 54, pp.936-944 (2021)

11. I. Malygin, O. Borodina, N. Shatalova, Airport network planning for Russia Arctic region, TRPP 1, pp.52-57 ISBN 978-5-6041745-9-3 (2020)

12. N. Shatalova, O. Borodina. Indicators of performed transportation work by civil aviation enterprises, TRPP 1, pp.145-150 ISBN 978-5-6041745-9-3 (2020)

13. ICAO doc 9060. Reference Manual on the ICAO Statistics Program 5 ISBN 978-929249-347-9 (2013)

14. A. Krylatov, V. Puzach, N. Shatalova, M. Asaul, Optimization of traffic lights operation using network load data, TRP 50, 321-329 DOI10.1016/j.trpro.2020.10.038 (2020) 